\title{
Fostering Students' Self-Esteem in Speaking by Extending Speaking Activities in Social Media
}

\author{
Yosefina Rosdiana Su${ }^{1}$, Fatmawati ${ }^{2}$, Ely Heldydiana Selamat ${ }^{3}$ \\ Universitas Katolik Indonesia Santu Paulus Ruteng, East Nusa Tenggara, Indonesia ${ }^{1,2,3}$ \\ Email: josephinesu517@gmail.com ${ }^{1}$ \\ Email: watti_f@yahoo.co.id ${ }^{2}$ \\ Email: ely.selamat@gmail.com ${ }^{3}$
}

\begin{abstract}
Speaking in foreign language involves both cognitive and psychological process which eventually bring it as the most challenging skill to learn. However, many learners do not have adequate opportunities to practice speaking unless in the classroom, thus, teachers and students needed to developed various extensive speaking activities including by utilizing technological features such as social media. This study is aimed at describing the students perceptions about extending speaking activities in social media and how it impact on the improvement of their skill as well as their selfconfidence in speaking. It was a case study involving 5 students of English Department in Universitas Katolik Indonesia Santu Paulus Ruteng, East Nusa Tenggara as the participants. The data were collected through observing the participants' English-Speaking videos posted on Facebook and Focus Group Discussion. The observation sheet and the discussion guidelines were used as the instruments of data collection. To analyse the data, the researchers used Miles and Huberman's procedures of data analysis, comprising: data reduction, data displaying, and conclusion drawing. This study revealed that, extending the speaking activities in social media had positively enhanced the students' speaking ability as well as their self-esteem in speaking.
\end{abstract}

Keywords: Extending, Self-esteem, Social media, Speaking skill,.

\section{INTRODUCTION}

Developing speaking skills is a vital priority for most language learners. Many learners believe that, the success of language learning can be easily measured through their ability to speak and carry out a conversation in the target language. For many EFL learners, speaking is considered as a high complex mental activity which differs from other language skills, in which, learners may suffer of weaknesses in their speaking performance because it requires greater effort of the central nervous system. There is a fact that the difficulties in speaking could be due to the disparity between the spontaneous nature of the spoken language and the structuring 
necessary to rearrange it into an acceptable and correct form of utterances (Hughes and Rebeca, 2002).

Furthermore, the difficulties in speaking usually deal with both cognitive and psychological aspects of the learner since speaking involves a challenging multifaceted cognitive process (Luoma, 2004) as well as the psychological condition such as the level of their self-esteem and their ability to cope with language anxiety (Bygate, 2006).

In EFL Classroom, Speaking is always challenging for both teachers and students. While students have to deal with their psychological and cognitive matters, creating an effective and meaningful speaking activities in the classroom is the challenge for many teachers of EFL. Providing the appropriate strategy of teaching speaking which can cover each individual's need. This could be worse when the teacher had to handle the large group consisted of more than 20 students. This kind of situation insisted most teachers to applied more effective strategies in order to keep the speaking class going communicative and efficient for each of learner.

However, the limited time allocation was usually mattering. Providing three to five-minute opportunities for each student to perform speaking was sometimes could not be well managed. Thus, to give more speaking chances for learners, teachers needed to promote an extensive speaking projects outside the class, so that they could also practice their speaking ability outside the classroom.

To be more effective, the project given should be purposeful in terms of improving their cognitive and psychological matters when dealing with speaking skill. In this case, the projects must be able to relieve the students feeling of anxiety which eventually improve their self-esteem (Wulandari 2019).
As one of the language skills, speaking is also taught as a core course in the curricula of English Department of Universitas Katolik Indonesia Santu Paulus Ruteng, East Nusa Tenggara. There are four (4) levels of speaking course, namely, Speaking for Daily Communication, Speaking for Argumentation, Speaking for Academic Purpose and Speaking for Debating, in this English department, speaking courses are offered from the first to the fourth semester.

In the course of Speaking for Daily Communication offered to the first semester's students, the lecturer applied an interesting extensive speaking activity which basically aimed at improving the students speaking ability as well as enhancing their learner motivation in learning speaking. The lecturer argued that enhancing their motivation in the first semester was crucial to shape and build the students' positive image about Speaking. The students were needed to be initially avoided from being afraid, shy, lack of motivation, and lack of self-confidence to speak.

To cope with this, the lecturer managed the students to develop an extensive speaking activity outside the classroom by utilizing the features of platforms such as Facebook, Instagram, or YouTube. The students were free to design their extensive speaking activities which can be done individually, in pairs, or in groups. Interestingly, some students had been excellently and consistently extending their speaking activities by recording their Englishspeaking videos in various topics and posted them into their Facebook walls.

In extending their speaking activities, this group of students applied systematic speaking process comprising: planning, rehearsing, recording, evaluating, revising, and uploading their videos in social media. The systematic process developed by this group of students had been successfully fostering 
their self-confidence to publish their videos in social media. This study was conducted to investigate the students' perceptions on the current issue and how it beneficial for themselves as the EFL learners.

\section{The Role of Self-Esteem in Improving Speaking Skill}

Self-esteem is the belief in our abilities that we are capable to do things successfully. In other word, it can be said that, self-esteem is an inner power which can encourage individuals to belief on their strength and ability in doing things including to be successful in learning. It is the psychological factors which is visibly stimulate us to overcome our feeling of anxiety in doing things.

Self-esteem is also defined as an emotion of how warm and loving you actually feel toward yourself, based on your individual sense of personal worth and importance (Barksdale1989). Brown (2007) in Navita (2016) emphasized that Self-esteem is one of the affective factors that influence human's development among many others and probably the most pervasive aspect of human behaviour.

Self-esteem has a very strong effect for the EFL learners, especially, in dealing with speaking tasks. In doing the speaking tasks, many learners experienced the feeling of anxiety which mostly derived from their difficulties in understanding what is being spoken and eventually assessed them to use the target language. They got reluctant to use the target language because they got afraid of making errors or mistakes (Naouel, 2015)

In relation to this ideas, both teachers and students need to recognize that there is a significant positive relationship between the student's self-esteem and their speaking improvement. Many studies in revealed that self-esteem has a powerful role in enhancing learners' oral performance in oral classes.
It was believed that, the tasks of speaking which involved both cognitive and affective activities cannot be successfully carried out without some degree of self-esteem (Brown, 2000 in Niki 2009). It is to say that, the higher the self-esteem is, the higher is the speaking achievement (Wesch, 2009).

For many EFL learners, self-esteem enabled them to be convinced to communicate their ideas in the target language or to deliver an oral presentation before the audiences. In other words, when a learner performs activities with confidence and without fear of failure, he is said to have high self-esteem (Navita, 2016). Thus, learners need to be encouraged to trust on their abilities and build their sense of selfesteem by motivating them through the use of a variety of activities that attract their interest and being relaxed in presenting the speaking tasks inside or outside the classroom.

\section{Extensive Speaking Activities in Social Media}

Social media enables individual to easily connect to the worldwide. The platforms like Facebook, Instagram, Whatsapp, YouTube, or Twitter assisted individuals to enhance their social connection (Christianson, et.al, 2009). However, social media is for good and evil. It is to say that, social media has both advantages and disadvantages.

The dark side of social media is related to the exploration of misinformation and how false information are constructed and adapted and had become the natural habitat of this digital age (Hamsley,2018). In this case, people can be easily connected to thousands of websites, blogs, groups, and alternative news sources amplify fake news and inaccurate information to such a degree that it impacts our intelligence collectively (Introne. et.al, 2018).

On the other hand, social media can also be used for good which can be so beneficial for its users in terms of extending the social 
engagement, supporting their wellbeing by improving the processing of information and cognitive functioning (Quinn,2018).

In terms of educational purposes, social media can help students to develop social capital (Ellison, Steinfield, \& Lampe, 2007). Teachers or students can easily share information, news, announcement or event class project through social media. Many teachers has even used social media as the learning tools or resources.

Vlogging of Video Bloggig is one of the features offered by platforms like Facebook, Instagram, or YouTube and become very popular among the teenagers. Through this feature, the users are free and can easily publishing their personal videos presenting kinds of topics or information for many purposes (Gao, Tian, Huang, \& Yang, 2010).

This digital feature is basically beneficial for EFL learners. Learners who learn speaking can utilize this feature to improve their speaking ability by recording their English speaking activities and publish it into the social media. Some researchers have revealed a number of advantages achieved through video recording activity for EFL learners.

Goktruk (2016) investigated the effect of utilizing video recording published on Facebook among the 10 Turkish EFL Learners. It was found that, the students' selfesteem in performing the oral presentation in the classroom had well improved with the used of this strategy. The researcher also recommended the EFL teachers to cooperate the digital video recording into speaking classes to enhance learners' self-confidence as well as promoting them to experiment with the target language by taking risks of being appreciated or evaluated by society.

\section{METHOD}

This study was aimed at examining the students' perception about extending the speaking activities in social media as a learning strategy in fostering their self-esteem in Speaking. This study was conducted as a case study involving five students of the first grade in English Department of Universitas Katolik Indonesia Santu Paulus Ruteng, East Nusa Tenggara as the participants. The participants of this study were students who has passed the course of Speaking for Everyday Communication and has developed an extensive speaking activity by utilizing the English-Speaking Digital Videos posted in Facebook. This group of students used their Facebook account to communicate their ideas in English, especially, to share the topics of their daily activities to their friends in social media.

The data were collected by two major techniques, comprising; Examine the videos of English Speaking Performance and Focus Group Discussion (FGD). Examine the videos was applied to evaluate the students speaking performance in terms of their grammar, content, vocabulary, fluency, and pronunciation to measure the improvement of their speaking performance as well as their selfesteem. In this stage, the researcher observing 30 videos produced by the participants. The researchers took 6 videos of each participants presenting 6 topics covered in the course of Speaking for Daily Communication.

In evaluating the participants' speaking performance, the researcher used the adapted scoring rubric of speaking as the instruments of evaluation. To explore the students' perceptions on the current topic, the researcher conducted a Focus Group Discussion involving the participants of this research. To help the researcher in managing a systematic discussion, the semi structured discussion guideline was used as 
the instrument. The researcher also used the video recording to record the discussion. In analysing the data, the researcher used Miles and Huberman's procedures of qualitative data analysis, comprising; data display, data reduction, and conclusion drawing.

\section{FINDINGS AND DISCUSSIONS}

Positive self-concept creates a strong selfesteem that will enable students to express their ideas, arguments, or concepts verbally with no hesitation. In this case, students' selfesteem is also affecting their motivation in learning and dong tasks.

As it is core to speaking performance, it can be stated that no speaking performance will be successfully carried out without strong self-esteem. Therefore, it is crucial for teachers to enhance students' self-esteem through appropriate language teaching strategy. The strategy is also expected can help the learners to believe on their individual strength, ability, knowledge of who they are, in short, how they appreciate themselves.

As stated before, the first-grade students of English Department in Universitas Katolik Santu Paulus Ruteng, East Nusa Tenggara were assigned to develop kinds of extensive speaking activities outside the class. The activities developed should consider the improvement of the learners' positive selfconcepts toward speaking skills. The activities were designed to diminish students feeling of anxiety, afraid, or being shy to speak which expected to be eventually shaping their strong self-confidence in speaking.

One of the activities designed was recording and posting the English Speaking digital videos in social media. The participants

of this research argued that this learning strategy was beneficial for them, since it has strongly enhanced their speaking ability as well as their self-esteem. Being encouraged to extend their speaking activities in social media was not only made them more familiar with the technology but enabled them to use the social media for a productive and advantageous purposes as stated below:

"I used social media, since I was in junior high school. I used to utilize my facebook account to share my photographs, updating the unimportant stories and yeah..sometimes I share hoax and, you know, it's embarrassing to me. But now, I can use my social media for a better purposes. Sharing my English speaking videos in facebook is my kind of pride. My friends said I'm cool, and you know, I makes me feel more confident to speak English. It's cool, right?" (MSB)

The transcript above reflected the students feeling of confidence as she get more appreciation from her friends in Facebook. she also learned to distinguished between positive and the negative aspects of social media, and being able to recognize her own foolish in understanding the function of social media.

To get a reliable information about the participants' extensive speaking activities in social media, the researchers had observed and evaluate the English Speaking videos posted by the participants' in Facebook. The videos being observed were the Project of Speaking For Everyday Communication Couse, thus, the topics were similar to each participants.

The total number of videos observed in this research was 30 . In this case, the researcher observed 6 (six) videos from each participant which presented 6 (six) different topics related to Speaking for daily communication. Below is the list of topics presented in the videos posted by the participants in Facebook:

Table 1: Participants' Video Content

\begin{tabular}{cllc}
\hline Video & \multicolumn{1}{c}{ Topics } & $\begin{array}{c}\text { Language } \\
\text { Focus }\end{array}$ & $\begin{array}{c}\text { Time } \\
\text { duration }\end{array}$ \\
\hline \multirow{2}{*}{$\mathbf{1}$} & This is Loys, & Simple & $\mathbf{2 - 3}^{\prime}$ \\
& $\begin{array}{l}\text { He's my } \\
\text { Classmate! }\end{array}$ & $\begin{array}{l}\text { present } \\
\text { tense }\end{array}$ & \\
\hline
\end{tabular}




\begin{tabular}{|c|c|c|c|}
\hline 2 & $\begin{array}{l}\text { What I like } \\
\text { to do in my } \\
\text { Spare times }\end{array}$ & $\begin{array}{l}\text { Simple } \\
\text { present } \\
\text { tense }\end{array}$ & $3-4^{\prime}$ \\
\hline 3 & $\begin{array}{l}\text { The Most } \\
\text { Embarrassing } \\
\text { Moment in } \\
\text { My Life }\end{array}$ & $\begin{array}{l}\text { Simple past } \\
\text { tense }\end{array}$ & $3-4^{\prime}$ \\
\hline 4 & $\begin{array}{l}\text { What did } \\
\text { you do last } \\
\text { weekend? }\end{array}$ & $\begin{array}{l}\text { Simple past } \\
\text { tense }\end{array}$ & $2-4^{\prime}$ \\
\hline 5 & $\begin{array}{l}\text { Maldives ,I'll } \\
\text { be there! }\end{array}$ & $\begin{array}{l}\text { Simple } \\
\text { future tense }\end{array}$ & $3-5^{\prime}$ \\
\hline 6 & $\begin{array}{l}\text { I want } \\
\text { to be an } \\
\text { Enterpreuner }\end{array}$ & $\begin{array}{l}\text { Simple } \\
\text { future tense }\end{array}$ & $3-4^{\prime}$ \\
\hline
\end{tabular}

Table 1 presented the general information of the videos produced by the 5 participants of this research. All the participants talked about the same topics on the video produced. Since the strategy was applied by the first grade students, the topics were closely related to their daily activities and emphasized on their awareness in using the basic grammar comprising; simple present tense, simple past tense, and simple future tense. As the EFL learners, the students were encouraged to communicate their ideas in English as well as being aware on the use of their English sentence structure.

On the video produced by the learners, there was a significant different in their performance. In the first to third videos, most students are considered to be less relaxed and produced more fillers like eeemmmm... ,uuuuhhhh...eerrrrrrr....and some other unwanted sounds which also affected their performance as seen below:

" hey...hello....my name's lidya. I'm the student of English Department of Saint Paul Catholic University of Ruteng. Eeemmm....eeemmmm.....i'd like to introduce of my classmate...eemmm.... yeahhh...eemmm...well...I have a friend, uuummmm...a best friend... eem....her name is Dena...uumm... she's 18 years old...eemm..she's from east Manggarai...uuummmm...she's very nice and yes...she umm...she's.. so cute....and beautiful. She likes shopping...eemmmm....she also likes eemmm....listening music...." (LEW)

The piece of transcript above was taken from a participant's video (LEW). In this piece of sentences, the speaker talked about the first topic dealing with introducing other. This is a common topic in English conversation but in this sample of utterences produced, the speaker used many fillers and the other unwanted sounds which influence her fluency in speaking.

However, the sentences produced had been well structured but the used of too many fillers made the speech sounded to be unclear. The sound of intonation and expression she produced clearly reflected her feeling of speaking anxiety. Moreover, the way she expressed her ideas reflected that the speaker was trying to tell something that had been memorized. This expression made the utterances sound to be unnaturally delivered.

To be more reliable, the researchers were evaluating the other videos produced by the same participants. Interestingly, it was found that, there was a difference between the participant's performance in the first paragraphs with the second to the last videos she posted in Facebook. It is to say that, the researcher examined an improvement on the next videos produced, in which, the speaker was considered to be more relaxed and confident in presenting her stories. The second topic was about hobby, and the speaker talked about what she did in her spare time. Below is the piece of transcript from the second video produced by the same speaker:

"Hello, this my second vlog, and I'd like to...yeah...sharing about what I like to do in my spare times. Well, uuhh... reading novel is my favorit thing to do. Yeaah... I read novel in my spare times, especially before I go to bed... 
you know?...um..reading novel is very entertaining to me. It also eem... broaden my understanding about many things. Oh yaa...my favorite novel is eemm...Harry Potter. Eem....i like all the reies of Harry Potter...it's incredible, you know?. Well, i...I have all the series of this novel, and if you guys are also interested to read...you contact me, okay? Don't worry guys, you can borrow it for free...I do! Hihihi..." (LEW)

The second video was produced in 2 minutes, and it was considered clearer and more understandable for the listeners. The speaker's expressions also reflected her feeling of confidence and less anxiety. The use of reinforcement such as guys..., you know, or the spoken clause structure such as well or so...impacted on the speech sounds as more natural than the first one. In this case, the researcher examined a positive improvement of the students' oral performance. The improvement was not only on her selfconfidence but also on the way she produced the spoken language form and the spoken grammar features.

As stated before, the researcher examined the improvement on the students' performance in each video they produced. Certainly, it can be assumed that, the more they practiced, the better they are. Below is the result of their speaking evaluation from the first to the last videos they made (1-6):

\begin{tabular}{|c|c|c|c|c|c|c|c|}
\hline \multirow[t]{2}{*}{$\mathrm{o}$} & \multirow{2}{*}{$\begin{array}{l}\text { Students' } \\
\text { Name }\end{array}$} & \multicolumn{6}{|c|}{ SCORE PER TOPICS } \\
\hline & & I & II & III & IV & $\mathrm{V}$ & VI \\
\hline 1. & MWR & 13 & 14 & 16 & 17 & 18 & 20 \\
\hline 2. & MSB & 12 & 13 & 15 & 18 & 18 & 19 \\
\hline 3. & LEW & 15 & 15 & 17 & 18 & 20 & 20 \\
\hline 4. & $\mathrm{ABY}$ & 10 & 13 & 15 & 16 & 16 & 18 \\
\hline 5. & $\mathrm{DNB}$ & 13 & 13 & 15 & 17 & 17 & 18 \\
\hline
\end{tabular}

Tabel 2: Result of Speaking Assesment

the data presented in the table above showed the result of the speaking assessment on the videos produced. In evaluating the student's performance, the researcher used the adapted scoring rubric which focused on assessing the aspects of fluency, pronunciation, vocabulary, syntax, and the overall used of English spoken form produced by each participants on the videos.

The score above obviously showed the improvement of the students' performance from the first to the last videos. The researcher examined that, in delivering the topics, the speakers could speak well using the standard English, in which the sociolect and the slang words were rarely appeared. The students were also trying to produce the academic speech which consider much on their grammar and avoid the mispronounce. The features of spoken language were also appear, such as, the use of informal language, contractions (I'd like to, I'd rather, I'll be coming back,etc), fillers (uum....eerrr...,etc) and intensifiers (totally cool, awesome, really sweet, etc).

Moreover, they also tried to utilize the discourse markers (well, oh, like, of course, yeah, etc). In this case, they tend to use the discourse markers for certain purposes such as to keep the listeners attention by saying: you follow me, right?, to mark the beginning of the new topic (anyway, I was going to tell the story) or to mark information that is new (oh really? I don't know, etc.).

Social media is a sort of networking site allows everyone to connect and following each other's profile. In this case, users of social media are able to view postings on their friends' feeds and provide respond by giving likes and commenting on posts. Likes and comments are posted publicly, so everyone follows the feed can see how many "likes" the post has collected to show the number of people favor the image or video. "Comment" feature also brings the communication into the whole new level allowing users to interact to each other toward posts with specific theme.

In relation to this issue, social media could help students to reflect upon themselves 
and being encouraged in taking risks of being evaluated by public. Recording and evaluating their own speaking performance could encourage them to reflect upon what they do and make such reflection to develop their own judgments of what goes on with themselves. Taking risk of being being liked or disliked, commented, evaluated or appreciated in social media could sharpen their awareness of what they are doing and heighten their ability to evaluate their own performance.

When they record and evaluated themselves, they were eventually lead themselves as the others saw them. This gave them a great insight into what they could do well, but also into the flaws. Watching themselves and watched by others will definitely make them more apparent and give them ample opportunity to reflect and to improve.

\section{How Speaking in Social Media Can Improve Students' Speaking Skill?}

This question is basically what the researcher intended to investigate in this study. The researcher was interested to explore the current topic from the students' points of view. To obtain the data, the researcher conducted the Focus Group Discussion (FGD) involving the 5 participants of this study. Through FGD, the participants are lead to discuss and share their experiences on how this extensive speaking strategy had been beneficial for them, especially, in improving their speaking skills.

Basically, all the participants agreed that this extensive speaking strategy had improve their speaking performance in the classroom and other English Speaking situations. They also highlighted that this strategy had effectively helped them to build their self-esteem and positive concept toward EFL learning as well as themselves individually. In the participants' point of view, there were three main reasons why this strategy worked well and encouraged their speaking skill as well as their self-esteem.

Firstly, It promotes more practices; in implementing this strategy, the students had to follow some procedure as portrayed in figure. English speaking self-concept had highest correlation with practicing strategy, in which, the practicing is considered as a good way to improve students' English speaking ability. Thus, students with high English speaking self-concept had more confidence to practice and had ability to put more time to practice. Below are the process applied by the participants and considered as the practicing strategy:

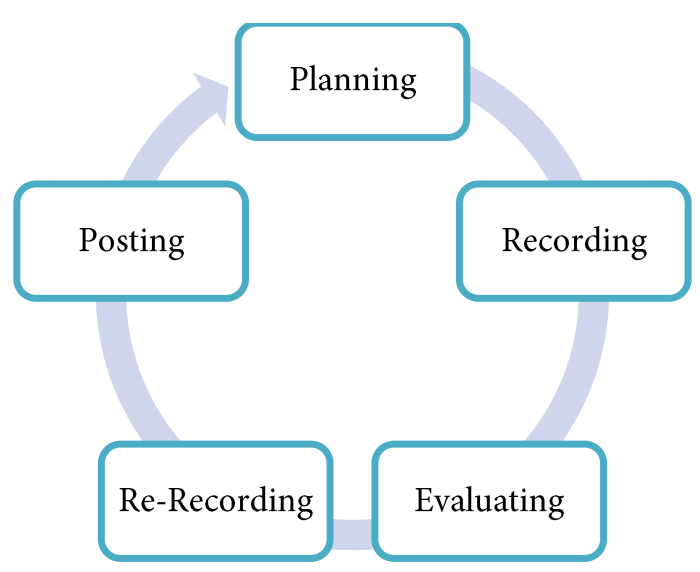

Figure 1: Cycle of Speaking Strategy

This cycle asserted that, although this strategy was considered as a fun learning, the students were permitted to apply the scientific process to get the best product to be offered to the public. This process insisted the students to rehearse and practicing more before the videos were uploaded in their social media.

Secondly, it promotes the encouragement in taking some "reasonable" risks and then selfrewarding. Students who had positive conceot on learning, often put continuous effort because they determined to do the best. So this strategy can effectively support their progresses in learning. 
Thirdly, it helps learners to overcome the limitations in Speaking. In this case, if one student had positive concept in learning Speking, he will be confident in English speaking and could be satisfied with his speaking ability. So during talking with others, he could try his best to overcome limitations in his speaking and he would use some compensatory techniques such as inference, use of gesture and mother tongues that could help him temporarily narrow the gap of understanding or expressing in English.

On their perceptions, following this procedure made them feel more confident to publish their videos in social media as stated below:

"I feel confident to post my English speaking videos on my facebook wall because before they were uploaded, I did such kind of evaluation on my own speaking performance. I noted my own grammar, the way I pronounce the English words. When I found errors or mistakes I re-record the video until I got the best one. It has to be done because the videos were going to be watched by public, my friends, my family, relatives, classmates, even my lecturers. This encouraged me to do my best, because, you know, I don't want to be looked ridiculous before my facebook friends..." (ABY)

This statement showed that by following this procedures, the students were eventually being able to notice their own strength and weaknesses in speaking. This was a reflective part of the strategy which allowed them to evaluate their own selves and attained to learn more for the best result.

Moreover, posting and allowing everyone on social media can encourage them to perform their best. Knowing that their videos will be freely access, commented, or evaluated by many people had stimulated them to be more improved. Having their friends' positive comments and appreciation on their performance was another motivation for the participants and eventually helped them to build a positive self-concept toward themselves as stated by a participant below:

"it is a challenging project but I felt that this project is much beneficial in improving my own speaking ability. I felt doubt and afraid at first, but after doing it three times, I felt much better and get more confident to record and post another video especially when my posts got more likes and comments from my friends" (DNB)

The students believe that, publishing their photographs or videos in social media were also impacted on publishing the positive self-image about themselves that will create such kind of impulse from within to achieve something called self-admission from others. It was also highlighted that, extending communication in social media was considered as another way for them to create an intrapersonal communication to record a moment with an implicit intention to attain positive comments of others upon themselves. And this what made each participant got more motivated to improve their speaking skill asa well as their self-esteem in doing the variety of speaking activities inside or outside the speaking class.

\section{CONCLUSION}

As the crucial factor in learning the speaking skill in EFL context, both teachers and students must recognize the significance of self-esteem in supporting the learning process. In this case, learners can perform the speaking tasks well when they have high selfesteem. Stimulating the learners' self-esteem is another task of all EFL teachers.

This article has obviously elaborated how social media can be utilized to extend the speaking activities, in which, the learners can express their ideas or stories in the target 
language. Posting the English speaking video performance in the paltforms like Facebook, Instagarm, or YouTube can improve students speaking skill as well as their self-confidence to communicate their ideas in the target language. This extensive practice of their speaking skill allowing them to reduce their anxiety when having to practice their speaking in front of the class

\section{REFERENCES}

Barksdate, L. S. (1989). Building self-esteem (2nd.ed). California: The Barksdate foundation

Bygate, M. (2009). Teaching the spoken foreign language. In B. Seidlhofer \& K. Knapp (Eds.), Teaching the Spoken Foreign Language (pp.401-438). Berlin: Mouton de Gruyter.

Christianson, M., Hoskins, C., \& Watanabe, A. (2009). Evaluating the Effectiveness of a Video-Recording Based Self-Assessment System for Academic Speaking. Language Research Bulletin, 24, 1-15.

Ellison, N. B., Steinfield, C., \& Lampe, C. (2007). The benefits of Facebook "Friends": Social Capital and College Students' Use of Online Social Network Sites. Journal of Computer-Mediated Communication, 12, 1143-1168.

Gao, W., Tian, Y., Huang, T., \& Yang, Q. (2010). Vlogging: A survey of Videoblogging Technology on the Web. ACM Computing Surveys (CSUR), 42(4), 15.

Göktürk, N. (2016). Examining the Effectiveness of Digital Video Recordings On Oral Performance of EFL Learners. Teaching English with Technology, 16(2), 7196.

Hemsley. Jeff, Jacobson2. Jenna. 2018. Social Media for Social Good or Evil: An Introduction. SAGE: Journal of Social Media and Society, July-September 2018: $1-5$
Hughes, Rebecca. (2002). Teaching and Researching Speaking. Pearson Education Limited: London

Introne, J., Iandoli, L., DeCook, J., Yildirim, I. G., \& Elzeini, S. (2017). The Collaborative Construction and Evolution of Pseudoknowledge in Online Conversations. In Proceedings of the 8th International Conference on Social Media \& Society. Toronto, Ontario, Canada: ACM.

Luoma, S. (2004). Assessing Speaking. Cambridge: Cambridge University Press

Naouel, B. (2015). The Role of Foreign Language Learners' Self- Esteem in Enhancing Their Oral Performance. International Journal of Multi Disciplinary Research, 2(2).

Navita. 2016. Role of Self-Esteem in English Speaking Skills in Adolescent Learners. Research Journal of English Language and Literature (RJELAL). Vol.4.Issue 4. 2016 (Oct.Dec.)

Niki Maleki, M., Mohammadi, A., M. (2009). Self-esteem and Anxiety of Iranian EFL Learners in Oral Communication Tasks. Journal of linguistic studies, 2 (2). $47-54$

Quinn, Kelly. 2018. Cognitive Effects of Social Media Use: A Case of Older Adults. SAGE: Journal of Social Media and Society, July-September 2018: 1 -9

Wulandari. Mega. 2019. Improving EFL Learners'Speaking Proficiency through Instagram Vlog. LLT Journal: A Journal on Language and Language Teaching , , Vol. 22, No. 1, April 2019

Wesch, M. (2009). YouTube and You: Experiences Of Self-Awareness in the Context Collapse of the Recording Webcam. Explorations in Media Ecology, 8(2), pp.1934. 